\title{
"Os tempos da história": temporalidades, mito e história em materiais didáticos de autores indígenas
}

\author{
Igor Scaramuzzi \\ Mestre em Ciência Social (USP) \\ Perquisador colaborador do Núcleo de História Indígena e do Indigenismo/USP - São Paulo \\ igorabs@hotmail.com
}

\begin{abstract}
Resumo Nas últimas décadas, muitos grupos indígenas vêm ampliando suas relações com diversos setores da sociedade nacional. Nesse contexto de intensificação dos embates e negociações com os não índios, as experiências de escolarização, especialmente aquelas desenvolvidas dentro do modelo "específico e diferenciado", constituem um importante espaço de produção discursiva que este artigo pretende enfocar. É no âmbito dessas experiências de escolarização que muitos grupos indígenas estão produzindo novos conhecimentos sobre seus saberes e experiências históricas. Nesses processos de produção de conhecimento, os materiais didáticos são um dos produtos mais significativos. Enfatizando esses processos, o presente artigo tem como objetivo analisar as concepções e formas de organização do tempo presentes em dez materiais didáticos cuja proposta principal é a escrita de narrativas sobre reflexões e experiências históricas vivenciadas por grupos indígenas. Busca-se analisar as formas de articulação entre conhecimentos e narrativas indígenas e as concepções ocidentais de conhecimento e transmissão de experiências históricas.
\end{abstract}

Palavras-chave: história indígena, educação escolar indígena, mito e história, conhecimentos tradicionais, letramento.

$\mathrm{N}$ as últimas décadas, muitos grupos indígenas vêm ampliando suas relações com os mais diversos setores da sociedade nacional. Nos mais variados espaços e contextos em que se dão essas relações, têm assumido a tarefa de elaborar discursos em que devem se apresentar, como grupos diferenciados, para o "outro".

Diante da crescente intensificação dos embates e negociações com os não índios, as experiências de escolarização, especialmente aquelas desenvolvidas dentro do modelo "específico e diferenciado", ${ }_{1}$ constituem um importante espaço de produção desses discursos políticos de autorrepresentação.

10 modelo de escolarização específico e diferenciado tem como principal diferencial em relação a outros modelos de escolarização implantados para populações indígenas anteriormente no Brasil o desenvolvimento de propostas político-pedagógicas que procuram levar em conta os anseios e necessidades de cada grupo indígena em relação à escola e que, ao mesmo tempo, possam auxiliar no fortalecimento das línguas, conhecimentos e processos próprios de ensino-aprendizagem de cada grupo indígena. Esse modelo começou a ser concebido nos anos 80 por organizações não governamentais com a proposta de elaborar e implantar projetos de ensino formal alternativos à política pública estatal. Esse modelo passou a ser implantado como política pública pelo governo federal nos anos 90 e atualmente é o modelo de escolarização recomendado para populações indígenas em todo o Brasil. Para o histórico da implantação do modelo no Brasil, ver Grupioni (2009). 
Além de espaço de produção e enunciação de discursos políticos, as experiências de ensino formal desenvolvidas dentro desse modelo também se configuram como formas importantes de produção de conhecimento, nas quais muitos grupos indígenas recriam, através da produção escrita em línguas indígenas e em língua portuguesa, suas maneiras de elaborar e transmitir conhecimentos e experiências históricas.

Levando em conta o principal objetivo e o pressuposto modelo de escolarização específico e diferenciado, que é a valorização e o fortalecimento dos conhecimentos e dos processos de ensino-aprendizagem encontrados em grupos indígenas, essa produção de conhecimento tem buscado abordar principalmente saberes produzidos em espaços e contextos não escolares, entendidos como "tradicionais". Nesses processos de produção de conhecimento em contexto escolar, os materiais didáticos têm sido um dos principais produtos.

Um dos tipos de materiais didáticos mais produzidos nessas experiências de escolarização, que constitui o objeto de reflexão deste artigo, são os que apresentam como proposta principal a escrita e a sistematização de conhecimentos e experiências históricas dos grupos indígenas. Em muitos materias didáticos desse tipo, especialmente os elaborados em língua portuguesa, professores indígenas e seus parceiros não índios ${ }^{2}$ se apropriam, na tarefa de escrita e sistematização dos conhecimentos e narrativas indígenas, de concepções, conceitos, categorias e formas de interpretação que compõem a filosofias da história e historiografias das sociedades ocidentais de tradição escrita.

Tendo como enfoque esses processos de produção de conhecimento ocorridos no âmbito do ensino formal específico e diferenciado, o presente artigo ${ }^{3}$ tem o objetivo de analisar as formas de conceber e organizar o tempo presentes em materiais didáticos com as características descritas no parágrafo acima. Dentro deste objetivo, pretende-se enfatizar como ocorre, na produção e na organização das narrativas que compõem os materiais didáticos, a articulação entre as temporalidades indígenas e o Ocidente, de tradição escrita.

Pretende-se incorporar à análise as formas de organização e classificação dos relatos nos materiais didáticos, os tipos de composição e os próprios relatos, o que inclui os prefácios escritos pelos organizadores não índios e os relatos e narrativas elaborados pelos professores indígenas.
Para tal tarefa, foram selecionados como referência dez materiais didáticos, elaborados no âmbito de cinco experiências de escolarização distintas, realizadas seguindo o modelo específico e diferenciado por cinco programas ou projetos de educação escolar indígena, a saber: Programa de Educação Uma Experiência de Autoria, da Comissão Pró-Índio do Acre (CPI-Acre); Programa de Implantação de Escolas Indígenas em Minas Gerais, Secretaria de Educação de Minas Gerais; Programa de Educação para os Povos Indígenas do Parque Indígena do Xingu, do Instituto Socioambiental (MT); Projeto Pirayawara, da Secretaria de Estado de Educação do Amazonas, e Programa de Formação Continuada de Educadores Índios Tupinikim e Guarani (ES), da Secretaria da Educação do Espírito Santo.

Os materiais didáticos selecionados, além da proposta de narrar e sistematizar concepções e experiências históricas de grupos indígenas, apresentam em comum o fato de terem sido todos elaborados em cursos de formação de professores indígenas e serem redigidos em português. Do total de dez materiais didáticos escolhidos para a análise proposta neste artigo, somente dois são bilíngues (língua indígena e língua portuguesa) e o restante (oito) foi escrito somente em português.

\section{Materiais didáticos e a escola específica e diferenciada}

A principal característica da vertente de escolarização atualmente vigente para os grupos indígenas no Brasil é a abordagem de conhecimentos indígenas no espaço escolar através da escrita em língua portuguesa e nas línguas indígenas. Na maioria dos lugares onde esse tipo de escolarização ocorre, a justificativa dos parceiros não índios e de lideranças e professores indígenas para a escrita e o uso desses conhecimentos no espaço escolar é o fortalecimento, a valorização e a manutenção das culturas, línguas e conhecimentos desses grupos, como mostra o trecho abaixo de um dos materiais didáticos:

Trata-se de uma coletânea de histórias das várias dimensões de seu saber tradicional e reflexões sobre o seu próprio processo histórico. Conscientes da importância de transmitir para as crianças este valioso patrimônio, os Maxacali adotaram o registro escri-

2 De forma geral, os parceiros são os idealizadores e elaboradores dos cursos de formação de professores indígenas e os responsáveis pela implantação das escolas. Na maioria das vezes, são organizações não governamentais, universidades, setores da Igreja Católica e da protestante e, atualmente, governos estaduais e municipais também.

3 Este artigo é uma versão de um capítulo sobre o mesmo tema que compõe minha dissertação de mestrado, em Scaramuzzi (2008). 
to como mais uma forma de perpetuar sua cultura. (Professores Maxacali, 1998, p. 9)

Além de serem usados dentro das escolas indígenas para o ensino-aprendizagem das disciplinas propostas nesse modelo, estão em alguns casos sendo produzidos e publicados em grandes tiragens para a venda e a divulgação, abrangendo um público de leitores não índios. ${ }^{4}$ Nos discursos que buscam justificar a produção desses materiais didáticos têm-se ressaltado, além do uso escolar, que a escrita de conhecimentos e experiências históricas veiculada por essas produções é uma forma de autorrepresentação e espaço de enunciação e tradução das diferenças culturais em relação a outros índios e não índios:

A presença no livro das versões em português das histórias dos antigos não foi uma decisão simples: num primeiro momento, os professores haviam decidido elaborar um livro só em Hãtxa kuii. Visavam o fortalecimento político e a valorização cultural da sua língua, sem colocá-la em relação, quase sempre desvantajosa, com a língua portuguesa. Após as discussões e alguns trabalhosos anos de escrita em língua indígena, entenderam ser importante que os mitos pudessem chegar às mãos das outras sociedades indígenas e dos leitores brasileiros em geral. (Kaxinawá; Monte, 2000, p. 18)

Por serem um importante espaço de ocorrência de produção e divulgação de discursos de autorrepresentação direcionados para públicos muito diversificados, desde leitores indígenas até leitores não índios, esses materiais didáticos configuram um rico corpus discursivo que, dada a diversidade de contextos em que tais discursos são elaborados e de interlocutores a que são destinados, se configuram como um tipo de produção discursiva multifacetada, ambígua e inovadora, como afirma Menezes de Souza:

Essa nova escrita indígena, especialmente a que é escrita em português, nasce paradoxal e simultaneamente local e nacional, marginal e canônica: local, porque cada comunidade com projetos para uma escola indígena se torna produtor/autor e consumidor/leitor de seus próprios textos; nacional, porque a política da escola indígena é federal, e isso faz com que surja um público consumidor/leitor potencial da escrita indígena em todas as escolas indígenas do país, fazendo com que esses livros possam circular para fora de suas comunidades produtoras e tornando as tradicionais sabedorias e valores das culturas indígenas (nas suas novas formas escritas) numa nova espécie de capital cultural transcomunitário; marginal, porque essa escrita, embora já prolífica e de grande abrangência, ainda não mereceu o interesse das academias e instituições literárias nacionais que, quando muito, a veem como uma espécie de literatura popular ou de massas, sem grande valor literário (quando alguns desses livros encontram o caminho para o mercado externo das livrarias nos grandes centros urbanos do país não é incomum encontrá-los na seção de Literatura Infantil); e finalmente canônica, porque se trata de uma escrita que já nasce no bojo da instituição escolar, com seus mecanismos de inclusão e exclusão curriculares que em várias culturas formam base para a construção, destruição ou transformação dos cânones literários. Não deixa de haver uma certa ironia no fato de que a escrita indígena, produto de um setor historicamente marginalizado como sendo "primitivo", já esteja formando, em menos de uma geração, seus próprios cânones da escrita. (2001, p. 71; grifos meus)

\section{Formas de organização e caracterização das narrativas que compõem os materiais didáticos}

Para a análise das concepções e formas de organização do tempo presente nos materiais didáticos, é primeiramente fundamental a descrição dos tipos de composição e das formas de diferenciação e organização dos relatos em tais materiais. Como se verá a seguir, os tipos de composição e de organização dos relatos adotados em cada produção escrita são de importância crucial nos modos como o tempo é concebido e organizado.

De forma geral, o que se encontra no conjunto de produções escritas é a composição de dois tipos de relatos que aparecem, na maior parte dos casos, distribuídos em partes separadas na organização desses materiais. O primeiro tipo de relato é denominado em parte das produções de "histórias de antigamente", "história dos antigos" ou "história das origens". O segundo tipo corresponde aos relatos denominados em alguns materiais de "histórias de hoje".

Independentemente dos critérios adotados em cada produção para a composição e a distinção dos dois tipos de relato, algumas características aparecem

4 Porém, esse público leitor não índio dos materiais didáticos indígenas ainda é muito pequeno. Praticamente se restringe ao círculo dos programas de educação da vertente específica e diferenciada e às instituições indigenistas. Existem algumas exceções, como é o caso do material produzido pela CPI-Acre Shenipabu Miyui (2000), que foi publicado em sua segunda edição pela editora UFMG e distribuído um pouco mais amplamente. 
de forma indistinta em todos os materiais didáticos analisados e seguem descritas a seguir.

Os relatos denominados "histórias de antigamente", "história dos antigos" ou "história das origens" compreendem um conjunto de narrativas que exibem como características marcantes aquelas associadas a narrativas que, na tradição escrita ocidental, convencionou-se chamar de mitos (Detienne, 1992; Vernant, 1992). Trata-se de "fragmentos míticos", que relatam episódios sobre a origem ou a criação de algo; o começo do mundo, a origem e a diferenciação dos homens, do fogo, de certas plantas cultivadas etc. Os enredos têm como personagens principais plantas, animais, seres sobrenaturais e os homens. Os personagens não humanos caracterizam-se por seu comportamento semelhante ao dos homens, ou seja, todos são dotados de agência, intencionalidade e se comunicam entre si e com os humanos através da fala.

Esses relatos remetem sempre a um passado remoto não vivenciado por ancestrais conhecidos nem por pessoas vivas. As fontes das informações dessas narrativas, os que supostamente vivenciaram essas experiências, não são conhecidas nem nomeadas. Para se referir a elas, são usadas categorias genéricas e distantes como "nossos ancestrais", "antepassados", "antigos", "os mais velhos", como mostra o exemplo abaixo:

Vamos contar uma história dos antigos. Em nossa fala chama-se, Nete Bekü, nome de uma mulher cega.

Diz que chegou um repiquete e alagou tudo. A água carregou essa mulher, que não teve por onde escapar. A alagação cobriu mato, terra, tudo. Terra alta também cobriu [...]. (Kaxinawá; Monte, 2000, p. 60; grifo meu)

É sempre recorrente nesse tipo de narrativa o uso de marcadores de tempo como "no começo de tudo", "há muito tempo atrás", "antigamente", para localizar a narrativa no passado distante e desconhecido:

\section{A origem do fogo}

Os mais velhos contam que bem no começo de tudo não existia quase nada. O pessoal da aldeia sentia muita falta das coisas. Uma das faltas que eles sentiam era do fogo. O pessoal só vivia assando ou moqueando peixes expostos ao raio do sol. (Professores do Parque Indígena do Xingu; Troncarelli, 1999, p. 85; grifo meu)

Um tema importante presente nesse tipo de relato diz respeito ao surgimento dos brancos. Como já enfatizado em muitos trabalhos de etnologia que abordam essa temática, como em Viveiros de Castro (2000), nesses relatos a origem dos brancos e, por consequência, os impactos e mudanças trazidos por eles aos grupos indígenas são sempre interligados direta ou indiretamente a escolhas e decisões tomadas pelos próprios índios, contrapondo a visão difundida por alguns setores da sociedade nacional de que os índios são vítimas e sujeitos passivos nas experiências de contato com os não índios:

\section{A história dos brancos}

Eu vou contar a história dos brancos. Antigamente não existia branco. Uma mulher foi no rio e a lagarta atravessou o caminho. A mulher gostou dela e à noite deitou com ela. Bem cedo ela saiu e dormiu lá em cima da árvore.

Quando a gente fez fogueira as lagartas se queimaram todas e viraram brancos.

Agora já tem branco. Índio nasceu primeiro, depois o branco saiu.

O homem que nasceu primeiro nós chamamos Iprëre, ele fez mulher e filhos. (Professores do Parque Indígena do Xingu; Würker, 1998, p. 16)

As narrativas denominadas, em alguns casos, como "histórias de hoje" tratam de uma infinidade de temas, mas os mais recorrentes são os relacionados às experiências de contato dos grupos indígenas com os não índios. Essas narrativas de tipo "histórico" têm sempre como personagens principais pessoas conhecidas pelos que estão vivos ou por seus ancestrais próximos. Os enredos estão relacionados a episódios testemunhados por essas pessoas e, portanto, remetem a períodos vivenciados tanto pelos vivos como pelos seus ancestrais conhecidos (reconhecidos pelo nome e na genealogia). Devido à finalidade de descrever com a maior objetividade possível o evento narrado, as fontes da informação são contextualizadas no espaço e no tempo pelos narradores e escritores. Como desdobramento desse objetivo de transmitir veracidade (no sentido da tradição escrita ocidental), ocorre o uso do calendário cristão como o principal referencial de tempo:

Por volta de 1870 os índios Munduruku lideraram a primeira revolta na região contra o português Luis Bentes, sob o comando de Manuel Tapajós Munduruku.

Luis Bentes morava dentro do igarapé Kwata, num lugar chamado Bom Futuro, no repartimento entre dois igarapés, Bom Futuro e Jará. A casa dele ficava bem na ponta, até hoje ainda aparece capoeira.

Depois começou ficar ruim não deixou mais os índios passarem para dentro do igarapé, nem para caçar, pescar ou tirar qualquer produto. (Palmeira, 2002, p. 47)

Nesses relatos, que narram eventos ocorridos em períodos vivenciados ou presentes na memória dos vivos, podem-se vislumbrar o impacto e as mudanças nos modos de vida dos grupos indígenas envolvidos nessas experiências: 
Por que nosso povo Jaminawá vive todo espalhado Com a chegada dos seringalistas e dos seringueiros caríus, a vida dos Jaminawá mudou muito. Não podiam mais caçar nem pescar libertos, porque por onde andavam as terras já estavam ocupadas por seringueiros nordestinos.

Os Jaminawá tiveram que se dividir em famílias quando passaram a sofrer as correrias dos peruanos e brasileiros. Alguns procuraram fugir para as cabeceiras dos rios e outros passaram a trabalhar pra patrões nos seringais.

Por isso, hoje são encontradas famílias de Jaminawá morando em aldeias do Peru, Bolívia e Brasil. No Acre existem terras indígenas Jaminawá no rio Iaco e nas cabeceiras do rio Acre. (Kaxinawá et al., s.d., p. 96)

Outra temática bastante significativa nas narrativas de tipo "histórico" é sobre o modo de vida desses grupos indígenas antes do contato efetivo com a sociedade nacional. Essas narrativas buscam mostrar como viviam anteriormente, como também as mudanças e as transformações pelas quais passaram esses grupos a partir do convívio permanente com os não índios. Um marcador importante usado para diferenciar os modos de vida pré e pós-contato é o termo "tradicional". Entende-se nessas narrativas como modo de vida tradicional aquele que ocorre sem os aparatos tecnológicos e de maneira independente dos não índios:

\section{A economia tradicional dos povos indígenas}

No tempo das malocas, cada povo indígena tinha seu território. Cada povo tinha sua própria organização, com seu governo, que era representado pelo seu chefe. O chefe organizava trabalhos na agricultura, as pescarias, as caçadas, as festas, os passeios, as correrias contra outros povos. Também aconselhava seu povo a viver unido.

Cada povo tinha sua economia tradicional. O trabalho dos homens era caçar, pescar, tirar lenha derrubar, plantar e limpar roçado. As mulheres faziam potes e camburões de barro, fiavam o algodão para amarrar flecha, teciam o algodão para fazer redes, tangas e pulseiras, preparavam tintas para enfeitar as pessoas e para pintar tecidos, arrancavam os legumes do roçado. (Kaxinawá et al., s.d., p. 67)

Nas narrativas sobre o período de pré-contato são sempre selecionados e ressaltados elementos culturais específicos, que correspondem com o que é comumente difundido sobre "indianidade" entre os não índios: divisão do trabalho entre homens e mulheres, moradia em malocas, uso de arco e flecha, pintura corporal, prática da agricultura, caça, pesca e artesanato, como mostra o trecho citado anteriormente. Nesses casos, o contato com os não índios funcio- na como um marcador de tempo significativo, tanto para diferenciar momentos distintos (a vida sem e com a presença constante dos não índios) como para salientar as permanências entre um momento e outro:

\section{Costumes antigos dos índios do Acre}

Antes do contato com os brancos, a gente só conhecia a nossa cultura. Muitos conhecimentos já faziam parte dela.

Hoje usamos muitas coisas fabricadas pelo branco. Mas muitos de nossos costumes permanecem nos dias de hoje.

O primeiro costume que prevalece é a nossa língua. Depois que acabou o cativeiro dos patrões, passamos a valorizar ainda mais a nossa língua, para nunca mais correr o risco de perder nossa cultura.

Hoje praticamos nossos hábitos de higiene, as pescarias de tingui, muitos de nossos cantos, nossa religião, a medicina da mata, nossas histórias de antigamente e nossas rezas para chamar os espíritos das plantações $[\ldots]$.

Estes são os trabalhos antigos. Os índios continuam vivendo os costumes de seu povo. Não querem viver de outra maneira. Os que esqueceram, estamos procurando trazer de volta. (Kaxinawá et al., s.d., p. 73)

\section{Temporalidades, mito e história}

Tendo como referência a composição na escrita dos dois tipos de relatos caracterizados anteriormente, em todos os materiais analisados, é possível depreender nos prefácios escritos pelos organizadores não índios, nos textos escritos pelos autores indígenas, como também na própria organização do conteúdo dos materiais, o uso de uma contraposição entre o que constituiria o mito - caracterizado nas produções escritas como relatos da criação e origem do mundo, dos homens, plantas e animais - e o que é tratado como "história", ou seja, referências a eventos ocorridos num tempo mais recente testemunhado pelas pessoas vivas ou pelos mortos reconhecidos nas genealogias.

Antes da análise dos critérios utilizados, é necessário ressaltar que tal distinção entre o que na tradição escrita ocidental se classifica como mito e história não faz jus às concepções de tempo imbuídas nos regimes de conhecimento indígenas e nas sociedades de tradição oral de forma geral.

Como evidenciam os clássicos trabalhos de Detienne (1992) e Vernant (1992), a distinção surgida entre mito e história se deu em um período histórico preciso entre os séculos VIII e IV a.C. (Vernant, 1992, p. 172), e em um contexto específico: a Grécia Antiga. Por outro lado, como evidenciam inúmeros 
trabalhos sobre grupos indígenas das terras baixas sul-americanas (como Overing, 1995; Turner, 1993), a articulação e as fronteiras entre o que se entende por "mito" e "história" não são nítidas nos regimes culturais ameríndios, e a ocorrência dessa distinção, quando tematizada em trabalhos de etnologia indígena, é adotada mais como ferramenta de análise do que como instrumento de representação das formas de pensamento desses grupos. Portanto, o que se estabelece de antemão é que a oposição entre mito e história não é universal, mas vem de um tempo e contextos específicos e acabou sendo incorporada pela tradição escrita ocidental em todas as áreas de conhecimento.

De forma geral, a diferenciação e o estatuto dado a cada tipo de relato (mítico e histórico) ocorrem no conjunto dos materiais analisados de acordo com dois critérios distintos.

A primeira forma de diferenciação é aquela que coloca as narrativas de tipo mítico no plano da ficção e as narrativas de tipo histórico no plano do real, ou da verdade. O mais interessante, nesses casos, é que tal critério de separação é afirmado somente pelos organizadores não índios desses materiais. Em nenhum dos casos em que prevalece essa oposição, ela é estabelecida pelos índios. Há casos, como o exemplo a seguir, encontrado em um material produzido no estado de Minas Gerais (Professores Xacriabá, 1997), em que a oposição é enunciada pela organizadora, na apresentação do material, e, nas páginas seguintes, contradita pelos enunciados indígenas:

Durante dois anos os professores Xacriabá em formação, no Programa de Implantação das Escolas Indígenas de Minas Gerais, realizaram uma pesquisa, nas suas aldeias, sobre as tradições de seu povo. Esse trabalho resultou na escrita de três tipos de texto:

- Narrativas em verso, de acontecimentos e fatos importantes na vida da comunidade Xacriabá: a luta pela posse da terra, a morte do líder Rosalino, a formação dos professores.

- Narrativas em prosa, do massacre ocorrido em 1987 na aldeia Sapé, no município de São João das Missões, quando Rosalino Gomes de Oliveira [...] foi assassinado.

- Coletâneas de contos tradicionais, que pertencem ao extenso universo ficcional mineiro, transmitidos oralmente de geração em geração.

(Professores Xacriabá, 1997, p. 6; grifo meu)

Caro leitor, foi pensando em você e em nosso povo que escrevemos o livro O tempo passa e a história fica. Nós queremos, através dele, lhe contar um pouco de nossa história. Esse livro é muito importante porque fala dos acontecimentos e das histórias reais. (Professores Xacriabá, 1997, p. 8; grifo meu)
Em um material produzido no estado do Espírito Santo, a classificação das narrativas míticas como ficção é colocada em oposição pela organizadora do material aos relatos "históricos" que, nesse caso, representam o real, o verdadeiro:

O primeiro livro retrata o imaginário mítico, a visão mágica de um mundo dos ancestrais inexoravelmente atravessado por valores e práticas estrangeiras. Tratase de um livro de histórias donde a mestiçagem cultural aparece em filigrana, constituindo mundos discursivos ficcionais. A punição como consequência de um incesto, a gravidez misteriosa que traz ao mundo um filho que se transforma em lagarta, o saci, a Maria Borralheira são temas e personagens de histórias por vezes trágicas, algumas vezes pueris. Histórias que saem da boca dos mais velhos e que se transformam pelo trabalho quase artesanal dos jovens educadores. Este segundo livro penetra os interstícios de fatos recentes, já não se trata mais de ficção, mas de um relato histórico de fatos vividos bem situados com relação ao aqui e agora. (Educadores Tupinikim e Guarani; Mugrabi, 2001, p. 9; grifos do autor)

Como já mencionado, esse critério de diferenciação e oposição que classifica o que entendemos por "mitos" como algo irreal, imaginário, fantasioso, e por "relato histórico" como forma discursiva dotada da razão e veracidade, não é de maneira alguma universal, como dão a entender os comentários citados anteriormente, mas historicamente datado e fruto de modificações nas formas de pensamento de grupos humanos específicos, como afirma Vernant:

Para que o domínio do mito se delimite em relação aos outros, para que através da oposição entre Mythos e Logos, dali em diante separados e confrontados, se desenhe a figura do mito própria da Antiguidade clássica, foi preciso toda uma série de condições cujo jogo, entre o oitavo e quarto século antes de nossa era, fez cavar, no seio do universo mental dos gregos, uma multiplicidade de distâncias, cortes e tensões internas. (1992, p. 172)

Para o caso dos povos ameríndios, há muito é sabido que tal distinção não é capaz de representar e compreender seus regimes de historicidade. Essa oposição está relacionada a alguns regimes de historicidade das sociedades ocidentais de tradição escrita, cujo conceito de "realidade" é relacionado com o que foi testemunhado e o que pode ser comprovado pelo testemunho documentado. Essa visão de "realidade" é o que embasa as formas de conceber a história nas sociedades ocidentais de tradição escrita e, por consequência, o que fundamenta também a contraposição entre o que alguns segmentos dessas sociedades clas- 
sificam como "mito" e o que é entendido por "história”, como afirma Overing (1995, p. 10):

[...] partimos do pressuposto de que o mito se opõe à história. Segundo nossa visão de mundo, a história diz respeito a eventos verídicos que seguem um percurso linear e progressivo, enquanto os eventos da mitologia não passam de realidades fantasmas, as quais são relativamente pouco relevantes quanto qualquer mundo real de ação e de experiência. Nossos próprios conceitos de realidade tendem a fornecer o padrão com base ao qual examinamos os conteúdos dos mitos, e é por esse motivo que boa parte da discussão geral sobre o mito gira em torno de questões que, de outro modo, seriam inexplicáveis. Assim os eventos míticos são contrapostos não somente à história, como também às descobertas científicas modernas referentes às propriedades físicas do universo.

Essa oposição disseminada pelas filosofias da história do Ocidente e ratificada em parte dos materiais didáticos analisados, além de colocar as narrativas míticas em juízo de valor em relação ao que se entende como "história", torna impossível compreender o sentido dessas formas de linguagem e pensamento nos sistemas de conhecimento em que são produzidas, como enfatiza Overing:

Como o mundo que é apresentado pelos ciclos míticos é considerado fantástico pelos cânones dessa realidade, a mitologia dos povos indígenas é um equívoco. Como muito de seus postulados sobre a realidade se exprimem mediante a exegese do mito, conclui-se, pois, que não se pode falar com propriedade de uma metafísica indígena. (1995, p. 112)

A outra forma de diferenciar mito e história, encontrada nos materiais didáticos, é aquela que ocorre por critérios temporais. Nesses casos, a distinção entre os tipos de relatos é baseada em concepções de tempo ratificadas nos modelos de historiografia ocidentais. Pode-se observar esse critério de distinção nos enunciados indígenas, nos prefácios escritos pelos organizadores, como na própria organização dos relatos nos materiais didáticos. Tendo como referência uma concepção de tempo linear, acumulativa e progressiva, as temporalidades distintas encontradas em cada tipo de relato são colocadas em sequência, estabelecendo-se uma continuidade cronológica entre ambas: o mito sempre antes da história. Nesse caso, o que se entende por mito, ao ser inserido nessa lógica temporal linear, cumulativa e cronológica, se transforma em um dos períodos da "história" de um determinado coletivo, como explicita o enunciado a seguir:

\section{A história indígena se divide em duas partes}

Na primeira parte estão os mitos, as histórias de antigamente. Cada povo explica de maneira diferente como foi que nasceram o mundo e os homens, o sol e a lua, os nomes das coisas, os bichos, os legumes, as festas, os remédios da mata, o cipó e todas as ciências. A segunda parte explica o que aconteceu em diferentes momentos da vida de cada nação indígena: as mudanças na organização, no governo e na economia, os conflitos entre as famílias, as guerras com outras nações. Estuda o tempo em que nossos povos não tinham contato com os brancos. Conta como vivíamos nas malocas, como eram nossos costumes, a nossa cultura tradicional: as festas, a medicina da mata, o artesanato, nossos vestuários, nosso governo. (Kaxinawá et al., s.d., p. 15)

Como evidenciado nas mais diversas etnografias sobre grupos indígenas das terras baixas sul-americanas, as narrativas míticas são, em alguns casos, de fato enunciadas e traduzidas pelos índios aos antropólogos e outros interlocutores como "histórias dos antigos", "histórias sobre os antigos" ou "histórias das origens", de forma semelhante à que aparece em alguns dos materiais didáticos analisados.

Em alguns contextos, como evidencia Farage (1997) para o caso dos Wapishana, alguns tipos de narrativas míticas podem constituir gêneros narrativos denominados pelos que as enunciam, sendo atribuído a essas narrativas certo grau de especificidade. É bem verdade também que seus enredos retratam um tempo não testemunhado pelas pessoas que as narram e que relatam em muitos casos acontecimentos ligados às origens, como explicado no trecho transcrito.

No entanto, mesmo com todas essas características, é muito difícil supor que os enunciados das narrativas míticas possam se inserir em um período cronologicamente anterior aos enunciados das narrativas de tipo histórico. Essa impossibilidade se dá basicamente por dois motivos.

Primeiramente, como já explicado, as fronteiras que separam o que entendemos por mito e história não são tão nítidas nas sociedades de tradição oral. Nos regimes de conhecimento encontrados nessas sociedades, os elementos que caracterizam cada um dos tipos de composição encontrados nos materiais didáticos (relatos míticos e históricos) não são segmentados, mas sempre articulados de forma específica, de acordo com diferentes contextos de enunciação. Mesmo que seja atribuída em contextos de oralidade alguma especificidade a elementos pertencentes ao que entendemos como mito ou história, essa atribuição não ocorre segundo as formas de distinção entre mito e história encontradas nas sociedades de tradição escrita ocidental.

O segundo ponto, o mais importante, é que as narrativas míticas não têm somente o estatuto de re- 
latos sobre um passado desconhecido e distante nas sociedades em que são enunciadas, mas também, e principalmente, funcionam como argumentos para explicar e entender o mundo.

Para defender tal hipótese, parto da concepção inaugurada pela abordagem de Lévi-Strauss, nos volumes das Mitológicas e nos livros que as seguiram, de que os mitos são uma forma específica de linguagem/ pensamento (Silva, 1995), um sistema de pensamento e comunicação (Vernant, 1992, p. 210) utilizado em outros regimes de conhecimento, que não o científico, para explicar o mundo. Esses regimes de conhecimento que se utilizam da linguagem/pensamento míticos são, da mesma maneira que o conhecimento de "tipo científico", motivados pelo desejo ou pela necessidade de explicar o mundo que os envolve (Lévi-Strauss, 1978, p. 31).

Muitos trabalhos etnográficos, baseados na abordagem de Lévi-Strauss, demonstram que as narrativas míticas são formas de expressar as explicações elaboradas no âmbito desses regimes de conhecimento acerca do mundo que os envolve, ou como afirma Overing: "É por intermédio do mito que os postulados referentes ao universo se exprimem e se explicam" (1995, p. 10). Para os observadores, como os antropólogos, as narrativas míticas são o principal meio de acesso a esses regimes de conhecimento, por onde aparecem os saberes cosmológicos desses grupos (Overing, 1995).

As narrativas míticas, por terem um papel reflexivo e explicativo nesses regimes de conhecimento, exibem no âmbito da tradição oral um caráter atemporal, e os enredos são enunciados em contextos específicos. Portanto, não são enunciadas na maior parte dos contextos narrativas "completas", mas, sim, referências aos repertórios conhecidos que não são apresentados como narrativas, mas como argumentos explicativos, como explica Gallois para o caso dos Wajãpi do Amapá:

Nesse ponto é importante lembrar que entre eles, os Wajãpi raramente narram mitos na forma de um discurso que representaria uma "versão integral". Em contextos muito particulares, para ensinar crianças, ou ensinar antropólogos, enunciam versões didáticas. Narrativas mais complexas são desempenhadas quando há debate sobre a interpretação de determinados eventos. Nos diálogos entre adultos os elementos míticos são apenas aludidos enquanto argumentos. (1994, p. 24)

Além de terem o papel de explicar a realidade, os argumentos empregados nessas narrativas são adotados como referência para as ações desses grupos diante de novas experiências históricas. Um exemplo notável é o conhecido trabalho de Sahlins intitulado
Ilhas de história (2003). Nesse trabalho, o autor mostra de forma contundente como os repertórios míticos foram utilizados tanto como argumentos para a interpretação de uma nova experiência histórica como serviram de referência para as ações dos polinésios diante de uma experiência nova, contribuindo de maneira fundamental para a série de acontecimentos que ocorreram na sequência dessa experiência. Por outro lado, demonstra que, justamente por serem argumentos e não narrativas fechadas, os repertórios míticos, ao se defrontarem com tal experiência, também sofreram transformações, foram renovados.

Para o caso das populações indígenas das terras baixas sul-americanas, são inúmeros os exemplos da relação entre os saberes expressos nas narrativas míticas e as práticas sociais desses grupos. São, na maior parte das vezes, esses saberes que embasam os repertórios de festas, rituais, resguardos e práticas de subsistência, como exemplifica Overing (1995, p. 126), sobre a relação dos saberes míticos com a maneira com que os Piaroa preparam e consomem a caça:

Tome-se como exemplo a questão da relação entre alguns dos postulados dos Piaroa a respeito da realidade e o modo como eles vivenciam essa realidade. Os Piaroa sustentam (primeiro postulado de realidade) que os animais eram/ são humanos no "tempo-antes" dos eventos míticos. Sustentam também (segundo postulado de realidade) que os animais só vivem na selva hoje porque seus ruwatu (xamãs especialistas) transformam os seres humanos do "tempo-antes" (que agora vivem com seus pais primordiais sob a terra) em animais e em seguida os transferem para a superfície da terra, para a selva. Portanto, a ingestão de animal é considerada um ato de canibalismo, e os Piaroa não comem carne que não tenha sofrido uma transformação, desta vez da forma animal para a vegetal (terceiro postulado de realidade), realizada pelos ruwatu. Os ruwatu realizam ambas as transformações - de seres humanos em animais e animais em vegetais - através de sua melopeia ritualística, à noite. Os Piaroa me informaram não sem um toque de humor irônico que eram vegetarianos. De fato o termo genérico que empregam para designar alimento é "comida vegetal" (Kwawa). Por fim (quarto postulado de realidade), eles afirmam que adoeceriam se comessem carne que não tivesse sido transformada em batata.

Pode-se concluir diante destes argumentos que a oposição entre mito e história adotada nos materiais didáticos pouco pode traduzir as formas de organização e expressão desses regimes de conhecimento. $\mathrm{O}$ que ocorre de fato, quando o conhecimento con- 
tido nos materiais é classificado e sistematizado segundo essa oposição, é a transformação desses saberes em conteúdos classificados e sistematizados em outro modo de conhecimento pautado por elementos da tradição escrita ocidental.

Portanto, organizar o conhecimento segundo essa oposição, utilizando a escrita, significa primeiramente transformar um conjunto de saberes empregados para explicar o mundo em tipos de composição de narrativas distintos, que segmentam características que são indissociáveis no âmbito da oralidade.

Em segundo lugar, significa cristalizar em narrativas completas e fechadas saberes que, em outros contextos, não são enunciados em todos os momentos como narrativas fechadas, mas também como argumentos explicativos sempre em constante renovação e transformação.

E, finalmente, seguindo os dois critérios utilizados para a diferenciação dos relatos encontrados nos materiais, os elementos míticos acabam sendo inseridos ou dentro do reino da ficção, que não faz sentido nos regimes de conhecimento em que são produzidos e transmitidos; ou são aprisionados em um "período da história" que abarca um passado remoto e distante, perdendo, nesse caso, seu caráter atemporal.

Pode-se notar, com os exemplos citados, que a continuidade desses regimes de conhecimento depende justamente da articulação dos elementos que são apresentados como opostos e segmentados nos materiais analisados. Como se pode supor, essa articulação só acontece se existirem espaços e condições para que as formas de produção, transmissão e expressão características desses regimes de conhecimento continuem ocorrendo, como afirma Gallois:

Esta seria, justamente, uma das características da transmissão oral: a narrativa não precisa ser completa nem a descrição exaustiva, pois é na forma dialógica e na retransmissão que o argumento se constrói e toma seu sentido. Depende, portanto, da continuidade da transmissão de símbolos próprios a cada cultura, em que as imagens reiteradas por um são ouvidas e realimentadas por outros. Ou seja, depende da manutenção de uma forma de transmissão participante: a oralidade. (1994, p. 26)

\section{Considerações finais}

Como se pode notar, as concepções e formas de organização do tempo, no conjunto dos materiais analisados, não conseguem se desvincular das concepções de temporalidade encontradas nos materiais didáticos utilizados nas escolas dos não índios, ou seja, uma concepção e uma organização do tempo baseadas em uma lógica linear, progressiva, cronológica e factual, que opera segundo as distinções entre natureza e cultura e entre mito e história. Essas formas de segmentação e oposição não correspondem àquelas encontradas nos regimes de historicidade indígenas ou de sociedades de tradição oral, em que esses elementos, visto que não são concebidos como opostos, são articulados de acordo com contextos específicos, sem que ocorra, diante disso, incoerências ou contradições (Overing, 1995, p. 130).

$\mathrm{O}$ que se pode observar nos materiais analisados é a inserção, sem uma contextualização adequada, de conhecimentos e narrativas indígenas em uma forma de organização e referência ao tempo que pertence aos regimes de conhecimento das sociedades ocidentais de tradição escrita, que pode ser claramente vislumbrada, por exemplo, na História como disciplina ministrada nas escolas dos não índios.

Esse manejo de conceitos e categorias pertencentes aos regimes de conhecimento da tradição escrita ocidental, feito de forma pouco crítica, também resulta em uma reflexão pouco apurada nas produções escritas dos autores indígenas sobre seus próprios modos de produzir e transmitir conhecimentos e pode dar a entender que categorias como mito e história que pertencem a regimes de conhecimento específicos, sejam universais, ou mesmo capazes de traduzir qualquer tipo de conhecimento sem transformá-lo.

Outra consequência decorrente da forma de união de conhecimentos indígenas e não índigenas sem uma devida contextualização é a pouca ênfase dada nas produções escritas ao próprio esforço de articulação em si, que envolve a tarefa de tradução cultural e que tem com resultado a construção de novos conhecimentos. Esse fato pode ter como desdobramento o entendimento por parte dos leitores de que, nos processos de sistematização de conhecimentos que ocorrem nesses materiais didáticos, há uma transferência de conhecimentos indígenas da oralidade para a escrita, como se os conhecimentos retirados de contextos de tradição oral e sistematizados nos materiais didáticos continuassem os mesmos nessa passagem.

As produções escritas analisadas, além de deixarem de evidenciar aspectos marcantes dos regimes de historicidade dos grupos indígenas, não conseguem demonstrar o potencial da escola e da escrita como meios importantes de tradução cultural e de criação de novos conhecimentos. Com a leitura desses materiais didáticos, que tratam como equivalentes conhecimentos que são produzidos e transmitidos em distintos espaços e regimes de expressão, os leitores, índios e não índios, podem perder a dimensão da capacidade ilimitada encontrada em todos os regimes de conhecimento, de renovação e transformação diante de novas experiências históricas, novos espaços discursivos e novas tecnologias. 


\section{Referências}

DETIENNE, Marcel. A invenção da mitologia. Brasília: José Olympio/UnB, 1992.

EDUCADORES ÍNDIOS TUPINIKIM E GUARANI; MUGRABI, Edivanda (Org.). Os Tupinikim e Guarani na luta pela terra. Brasília: MEC/SEF, 2001. (Publicação em português).

FARAGE, N. As flores da fala. 1997. Tese (Doutorado-Departamento de Letras Clássicas e Vernáculas) - Faculdade de Filosofia, Letras e Ciências Humanas, FFLCH-USP, 1997. GALLOIS, D. T. Mairi revisitada. A reintegração da Fortaleza de Macapá na tradição oral dos Waiãpi. São Paulo: Núcleo de História Indígena e do Indigenismo da Universidade de São Paulo/Fapesp, 1994.

GRUPIONI, L. D. B. Olhar longe, porque o futuro é longe - cultura, escola e professores indígenas no Brasil. 2009.

Tese (Doutorado - Departamento de Antropologia Social) - FFLCH-USP, 2009.

KAXINAWÁ, J. \& MONTE, N. (Orgs.). Shenipabu Miyui: história dos antigos. Belo Horizonte: Ed. da UFMG, 2000. (Publicação bilíngue: português e língua kaxinawá).

KAXINAWÁ, J. P. M. et al. Índios no Acre. História e organização. Rio Branco: Comissão Pró-Índio do Acre, s.d. (Publicação em português).

LÉVI-STRAUSS, C. Mito e significado. Lisboa: Edições 70, 1978.

MENEZES DE SOUZA, L. M. De estória à história: a escrita indígena no Brasil. Revista da Biblioteca Mario de Andrade, v. 59, 2001.

OVERING, J. O mito como história: um problema de tempo, realidade e outras questões. Mana, v. 1, n. 1, Rio de Janeiro: UFRJ, 1995.

PALMEIRA, F. (Org.). Kwata-Laranjal, história e reconquista da terra. Manaus: Seduc, 2002. (Publicação em português). PROFESSORES DO PARQUE INDÍGENA DO XIN-
GU \& TRONCARELLI, M. C. Histórias de hoje e de antigamente. Brasília: ISA/MEC/RFN, 1999. (Publicação em português).

PROFESSORES DO PARQUE INDÍGENA DO XINGU \& WÜRKER, E. Livro de história, v. 1. Brasília: ISA/ MEC/RFN, 1998. (Publicação em português).

PROFESSORES MAXACALI. Môndyxop 'ãgtux yôg tappet: o livro que conta as histórias de antigamente. Belo Horizonte: MEC/SEE-MG, 1998. (Publicação bilíngue: língua maxacali e português).

PROFESSORES XACRIABÁ. O tempo passa e a história fica. Belo Horizonte: MEC/SEE-MG, 1997. (Publicação em português).

SAHLINS, Marshall. Ilhas de história. Rio de Janeiro: Jorge Zahar, 2003.

SCARAMUZZI, I. De índios para índios: a escrita indígena da história. 2008. Dissertação (Mestrado - Faculdade de Filosofia, Letras e Ciências Humanas) - Universidade de São Paulo, São Paulo, 2008.

SILVA, Aracy Lopes da. Mito, razão, história e sociedade: inter-relações nos universos socioculturais indígenas. In: SILVA, Aracy L. da; GRUPIONI, Luís Donisete B. (Orgs.). A temática indígena na escola: novos subsídios para professores de $1^{\circ}$ e $2^{\circ}$ graus. Brasília: MEC/MARI/Unesco, 1995.

TURNER, T. Da cosmologia à história: resistência, adaptação e consciência social entre os Kaiapó. In: CARNEIRO DA CUNHA, M. \& VIVEIROS DE CASTRO, E. (Orgs.). Amazônia: etnologia e história indígena. São Paulo: NHII/USP \& Fapesp, 1993.

VERNANT, Jean-Pierre. Mito e sociedade na Grécia Antiga. Rio de Janeiro: José Olympio, 1992.

VIVEIROS DE CASTRO, E. A história em outros termos. Povos indígenas no Brasil. São Paulo: Instituto Socioambiental/ISA, 2000. 


\title{
"Times of History": temporality, myth and history in school books by indigenous authors
}

\begin{abstract}
During the last decades, many indigenous groups have increased their relations with various sectors of national society. Within this context of more intense contact and negotiation with non-indigenous society, school experiences, especially those developed according to a "specific and differentiated" model of schooling, are an important place of discursive production, which this article intends to focus upon. It is within these schooling experiences that many indigenous groups are producing new knowledge concerning their own knowledge and historical experiences. In these processes of knowledge building, the school materials such as, text books, are the most significant products. Emphasizing these processes, the present article aims to analyse the conceptions of time and the different ways of organizing it in ten differents school text books, that have the underlying proposal of writing narratives concerning reflections and historical experiences of indigenous groups. The article seeks to analyse the relations among knowledge and indigenous narratives and western conceptions of knowledge and transmission of historical experience.
\end{abstract}

Key words: indigenous history, indigenous school education, myth and history, traditional knowledge, literacy.

\section{"Los tiempos de la historia": temporalidades, mito y historia en materiales didácticos de autores indígenas}

\section{Resumen}

En las últimas décadas, muchos grupos indígenas han ampliado sus relaciones con diversos sectores de la sociedad nacional. En ese contexto de intensificación de los embates y negociaciones con los no-indígenas, las experiencias de escolarización, sobre todo aquellas desarrolladas dentro del modelo "específico y diferenciado", constituyen un importante espacio de producción discursiva, el cual este artigo busca enfocar. Es en el ámbito de esas experiencias de escolarización que muchos grupos indígenas producen nuevos conocimientos sobre sus "saberes" y experiencias históricas. En esos procesos de producción de conocimiento, los materiales didácticos son uno de los productos más significativos. Enfatizando esos procesos, el presente artigo tiene como objetivo analizar las concepciones y formas de organización del tiempo presentes en diez materiales didácticos cuya propuesta principal es la escrita de narrativas sobre reflexiones y experiencias históricas vividas por grupos indígenas. Buscase analizar las formas de articulación entre conocimientos y narrativas indígenas y las concepciones occidentales de conocimiento y transmisión de experiencias históricas.

Palabras-clave: historia indígena, educación escolar indígena, mito y historia, conocimientos tradicionales, escritura.

Data de recebimento do artigo: 21/12/2010

Data de aprovação do artigo: 5/5/2010 